\title{
Cardiac tamponade as a rare complication of pediatric perforated appendicitis
}

\author{
Bibek Saha, BMSc $\cdot$ Kazuyoshi Aoyama, MD, PhD 무 \\ Mark Levine, MBBCh, FRCPC
}

Received: 25 October 2019/Revised: 5 November 2019/Accepted: 5 November 2019/Published online: 14 November 2019

(C) The Author(s) 2019

\section{To the Editor,}

Acute appendicitis is the most common pediatric general surgical emergency. ${ }^{1}$ Although classic symptoms are well known, they are uncommon and often misinterpreted in pediatric patients, potentially delaying diagnosis and resulting in rare complications. ${ }^{2,3}$ Pericardial effusion and/ or pericarditis secondary to perforated appendicitis has been described in pediatric patients. ${ }^{4}$ We report the first case of cardiac tamponade, a life-threatening condition resulting in hemodynamic compromise, due to appendicitis.

A seven-year-old girl (whose parents consented to this report) presented to the emergency department with chest pain, shortness of breath, epigastric abdominal pain, retching, and constipation. The symptoms began three days after a classmate punched her on the chest. Upon

Electronic supplementary material The online version of this article (https://doi.org/10.1007/s12630-019-01529-y) contains supplementary material, which is available to authorized users.

B. Saha, BMSc

John A. Burns School of Medicine, University of Hawaii at Manoa, Honolulu, HI, USA

Department of Anesthesia and Pain Medicine, The Hospital for Sick Children, Toronto, ON, Canada

K. Aoyama, MD, $\mathrm{PhD}(\varangle)$

Department of Anesthesia and Pain Medicine, The Hospital for Sick Children, Toronto, ON, Canada

e-mail: kazu.aoyama@utoronto.ca

Program in Child Health Evaluative Sciences, The SickKids Research Institute, Toronto, ON, Canada

M. Levine, MBBCh, FRCPC

Department of Anesthesia and Pain Medicine, The Hospital for Sick Children, Toronto, ON, Canada physical examination, she was tachycardic, normotensive, afebrile $\left(36.2-37.1^{\circ} \mathrm{C}\right)$, and showed hepatomegaly, congested neck veins, and muffled heart sounds. Because of elevated c-reactive protein (CRP) and white blood cell (WBC) count $\left(15.0 \times 10^{9} \cdot \mathrm{L}^{-1}\right)$, ceftriaxone and vancomycin were empirically administered to treat possible infection. Findings of cardiomegaly on chest radiography (Figure A); low QRS voltages on the electrocardiogram; and echocardiographic evidence of right atrial and ventricular collapse, a dilated inferior vena cava, a large pericardial effusion, and a swinging heart all pointed to a diagnosis of tamponade. She proceeded to have a pericardiocentesis under conscious sedation while maintaining spontaneous ventilation with ketamine, midazolam, morphine, and local anesthesia. ${ }^{5}$ The patient remained hemodynamically stable throughout the procedure during which sanguineous fluid was aspirated. The fluid tested negative for viral, bacterial, and fungal infection. The next day, the patient developed a right-sided pleural effusion (Figure B), tachypnea, and was febrile. Chest tube drainage of serous fluid was again negative for bacterial culture.

Two days later, the patient developed nausea, emesis, guarding, a possible psoas sign, with the abdominal pain relocated to the right lower quadrant. Based on the clinical findings, ultrasound exam, and later pathological analysis, a diagnosis of acute suppurative appendicitis with perforation was made. She subsequently underwent uneventful laparoscopic appendectomy under general anesthesia, which included propofol, midazolam, fentanyl, and rocuronium. Anesthesia was maintained with sevoflurane and morphine. Upon followup, the patient appeared well and had returned to school.

The differential diagnosis for the pericardial effusion etiology included autoimmune/rheumatologic diseases, malignancy, infection, trauma, and a systemic inflammatory response syndrome (SIRS) to the appendicitis. Based on 


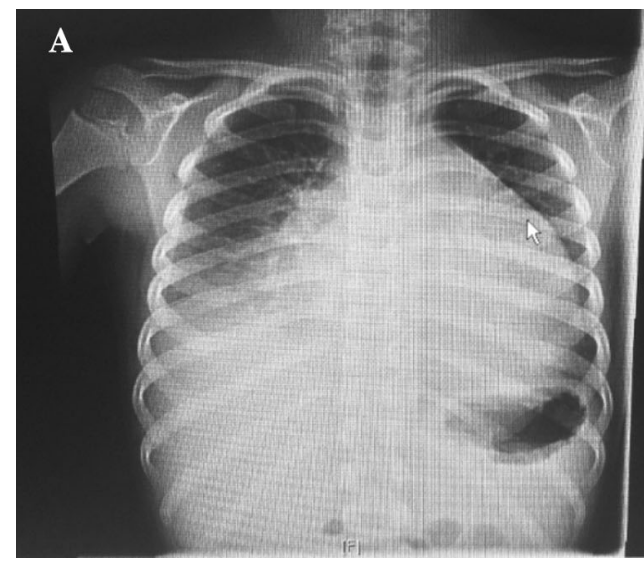

Figure Chest radiographs of a seven-year-old girl who presented with cardiac tamponade and was subsequently diagnosed with perforated acute suppurative appendicitis. A) An upright chest radiograph showing an enlarged cardiac silhouette indicative of

clinical presentation, including the absence of joint pain and rash, as well as negative anti-dsDNA, anti-ENA, and ANCA, an autoimmune/rheumatologic cause was unlikely. Her normal $\mathrm{C} 3$ and $\mathrm{C} 4$ levels, and the absence of protein and blood in the urine strengthened this assumption. Secondly, evidence such as lack of mediastinal masses and lymphadenopathy ruled out malignancy as a cause. Finally, the negative viral, bacterial, and fungal assays made an infectious cause unlikely. In contrast, since the CRP and WBC count were elevated for most of the patient's admission, it is likely that the tamponade was secondary to SIRS caused by the perforated appendix. Prior awareness of this relationship may have promoted earlier abdominal imaging and appendectomy, given the gastrointestinal symptoms. One limitation of our report is that we were unable to exclude chest trauma as the cause. Nevertheless, this is unlikely given that the source of the blunt trauma was a seven-year-old boy of medium build, and the force was not great enough to knock the patient down.

An extensive literature review (see eTable in the Electronic Supplementary Material) identified several similar case reports that described unique complications of perforated appendicitis, specifically pericardial effusion and/or pericarditis. ${ }^{4}$ Nevertheless, this is the only report to our knowledge of a child developing tamponade secondary to a ruptured appendix. Awareness of this uncommon relationship has prognostic value as this may facilitate earlier recognition and management of pericardial effusions, tamponade, or appendicitis, thereby improving patient outcomes.

Acknowledgements 2019 Perioperative Services Summer Studentship Program, the Hospital for Sick Children. Ms. Marina Englesakis, MLIS for her support of literature search.

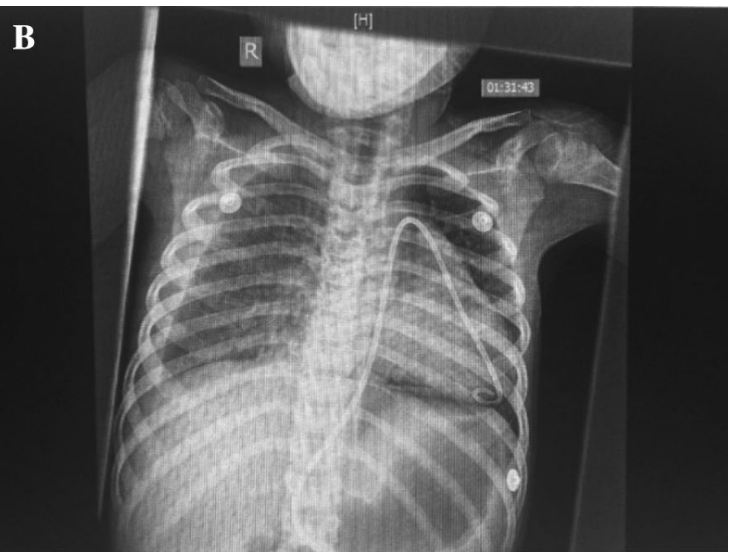

cardiomegaly and a right-sided pleural effusion. B) A supine chest radiograph the day after pericardiocentesis showing a diminished cardiac silhouette with a pericardial drain in situ and the persistent right-sided pleural effusion

\section{Conflicts of interest None.}

Funding statement This research received no specific grant from any funding agency in the public, commercial, or not-for-profit sectors.

Editorial responsibility This submission was handled by Dr. Hilary P. Grocott, Editor-in-Chief, Canadian Journal of Anesthesia.

Informed consent Written informed consent was obtained from the patient and parents for their anonymized information to be published in this article.

Ethical approval The Hospital for Sick Children has waived an ethical approval for this publication as per the hospital privacy policy. As such, we have registered the consent obtained from the patient and parents to the depository of the hospital Research Ethics Boards.

Open Access This article is distributed under the terms of the Creative Commons Attribution-NonCommercial 4.0 International License (http://creativecommons.org/licenses/by-nc/4.0/), which permits any noncommercial use, distribution, and reproduction in any medium, provided you give appropriate credit to the original author(s) and the source, provide a link to the Creative Commons license, and indicate if changes were made.

\section{References}

1. Podany $A B$, Tsai $A Y$, Dillon $P W$. Acute appendicitis in pediatric patients: an updated narrative review. J Clin Gastroenterol Treat 2017; DOI: https://doi.org/10.23937/2469-584X/1510042.

2. Rentea RM, St. Peter SD. Pediatric appendicitis. Surg Clin North Am 2017; 97: 93-112.

3. Cappendijk VC, Hazebroek $F W$. The impact of diagnostic delay on the course of acute appendicitis. Arch Dis Child 2000; 83: 64-6. 
4. Ku D, Cassey JG, Mejia $R$. Pericardial effusion as a rare complication of a perforated appendicitis. Int J Surg Case Rep 2017; 35: 98-100.

5. De Carlini CC, Maggiolini S. Pericardiocentesis in cardiac tamponade: indications and practice aspects. eJournal of Cardiology Practice - 2017. Available from URL: https://www. escardio.org/Journals/E-Journal-of-Cardiology-Practice/Volume-
15/Pericardiocentesis-in-cardiac-tamponade-indications-andpractical-aspects (accessed November 2019).

Publisher's Note Springer Nature remains neutral with regard to jurisdictional claims in published maps and institutional affiliations. 